Grand Valley State University

ScholarWorks@GVSU

2015

\title{
A Critique of the Ubiquity of the Toulmin Model in Argumentative Writing Instruction in the U.S.A.
}

Lindsay M. Ellis

Grand Valley State University, ellisl@gvsu.edu

Follow this and additional works at: https://scholarworks.gvsu.edu/eng_chapters

Part of the Arts and Humanities Commons

\section{ScholarWorks Citation}

Ellis, Lindsay M., "A Critique of the Ubiquity of the Toulmin Model in Argumentative Writing Instruction in the U.S.A." (2015). Book Chapters. 1.

https://scholarworks.gvsu.edu/eng_chapters/1

This Article is brought to you for free and open access by the English Department at ScholarWorks@GVSU. It has been accepted for inclusion in Book Chapters by an authorized administrator of ScholarWorks@GVSU. For more information, please contact scholarworks@gvsu.edu. 


\title{
A Critique of the Ubiquity of the Toulmin Model in Argumentative Writing Instruction in the U.S.A.
}

\section{LINDSAY M. ELLIS}

\author{
English Department \\ Grand Valley State University \\ U.S.A. \\ ellisl@gvsu.edu
}

\begin{abstract}
Secondary and university instructors in the United States rely heavily on the Toulmin model to teach written argumentation. To date, pragma-dialectics (van Eemeren and Grootendorst 2004; van Eemeren 2010) is not a visible presence in American composition textbooks. To ameliorate the limits of a single framework, writing instructors and consultants should ask critical questions not only associated with Toulmin's model, but also those of the pragma-dialectic model of critical discussion.
\end{abstract}

KEYWORDS: composition, critical thinking, critical questions, pragma-dialectics, teaching, Toulmin model, United States of America, writing

\section{INTRODUCTION}

When teaching written argumentation, both secondary and university instructors in the United States of America rely heavily on the Toulmin model (Hillocks 2011; Ramage, Bean and Johnson 2001; Smith, Wilhelm, and Fredricksen 2012). No other theoretical models of argumentation are as prominent in English composition textbooks and curricula, and the reach of the Toulmin model extends into science and math education as well (Chin \& Osborn 2010; Enduran, Osborne, \& Simon 2004; Krummheuer 1995)

In the newly adopted Common Core State Standards for elementary and secondary education in the U.S., argumentative writing is heavily emphasized. As a result, a flurry of new books and curricula on teaching argumentative writing have been published in the last five years. One can see how predominant the Toulmin model is by simply flipping the pages of Teaching Argument Writing by George Hillocks (2011, xix) and Oh Yeah? Putting Argument to Work Both in School and Out by Michael W. Smith, Jeffrey Wilhelm, and James Fredricksen $(2012,12)$. Why is this the case?

Writing instructors have tragically little time to read the large body of research and scholarship pertaining to the many facets of their work. The Toulmin model is probably the backbone of most argumentative writing curricula in the United States because it is visually accessible and explicable. Teachers are able to quickly digest and apply the visual representation of its central concepts.

Second, the Toulmin model seems helpful because it defines one vocabulary that enables discussion of the elements of an argument: claims, data, qualifiers, rebutting conditions, and warrants. When facing common problems in writing instruction, the Toulmin model provides educators a schema for diagnosis and treatment. It allows teachers to focus attention and facilitate discussion about these elements. Helping students to invent and include these elements in their papers is much of the substance of current written argumentation curricula. 
This article steps back and examines the American reliance on the Toulmin model from a distance--metaphorically from the University of Amsterdam, where the pragmadialectical model of argumentation holds the privileged place that Toulmin's does in the U.S.A. (Van Eemeren and Grootendorst 2004; Van Eemeren 2010). Some of the problems that U.S. teachers face when teaching argumentative writing might be problems not that the Toulmin model can help them to effortlessly solve, but ones that a reliance on Toulmin might be intensifying.

\section{COMMON PROBLEMS}

After working with writing instructors at all levels for the last ten years, I have observed a pattern of common problems and complaints from writing teachers and tutors.

\begin{tabular}{|c|c|c|}
\hline & Common complaint & Common instructional comment \\
\hline O & $\begin{array}{l}\text { A student says, "I don't know what to } \\
\text { write about," when asked to write about } \\
\text { a text that she has read. }\end{array}$ & "What's your topic?" \\
\hline O & $\begin{array}{l}\text { A student drafts a text, but the main } \\
\text { claim is a commonplace. It is not } \\
\text { contestable. }\end{array}$ & "Who would disagree with that?" \\
\hline O & $\begin{array}{l}\text { A student states a controversial } \\
\text { opinion, but offers no evidence to } \\
\text { support it; he merely restates the } \\
\text { opinion multiple ways. }\end{array}$ & "You haven't told me why you believe this." \\
\hline O & $\begin{array}{l}\text { A student relies formulaically on a five- } \\
\text { paragraph theme structure: stating a } \\
\text { claim in the first paragraph, giving } \\
\text { three reasons in three subsequent } \\
\text { paragraphs, and restating the claim in } \\
\text { the concluding paragraph. }\end{array}$ & "I see you have five paragraphs." \\
\hline O & $\begin{array}{l}\text { A student states a claim and cites others } \\
\text { who agree, but doesn't acknowledge or } \\
\text { address the complexity of the issue. }\end{array}$ & "Can you imagine any objections to this idea?" \\
\hline O & $\begin{array}{l}\text { A student states a claim and cites data, } \\
\text { but doesn't explain how the data } \\
\text { supports the claim. For example, she } \\
\text { includes quotes from a novel in a } \\
\text { literary analysis paper, but does not } \\
\text { offer interpretation. }\end{array}$ & "What does this quote mean to you?" \\
\hline
\end{tabular}


When coaching student writers who need help addressing these problems, the Toulmin model is a useful tool for certain things. It helps us to visually remind writers that claims need support, that support needs to be warranted, and that qualified claims aren't weak, they are responsible. The Toulmin model is not, however, a heuristic for deliberation. It does not describe or assist the process of developing claims by thinking critically through the implications of possible stances on tough intellectual issues. Stephen Toulmin states this explicitly. The task he tackled in The Uses of Argument (1958) was to describe how already-held opinions might be justified logically:

We are not in general concerned in these essays with the ways in which we in fact get to our conclusion, or with methods of improving our efficiency as conclusiongetters. It may well be, where a problem is a matter for calculation, that the stages in the argument we present in justification of our conclusion are the same as those we went through in getting at the answer, but this will not in general be so. In this essay, at any rate, our concern is not with the getting of conclusions but with their subsequent establishment by the production of a supporting argument. (16-17)

Because I believe that it is vitally important that we do teach the process of coming to good decisions, of reasoning one's way to conclusions carefully, I think American teachers and tutors of writing need to supplement Toulmin's model in our teaching argument writing toolbox.

\section{DIFFERENCES IN WRITING TASKS}

In fact, beyond the Toulmin model diagram, a whole field of argumentation studies is thriving. In the Netherlands, secondary and university level instruction in argumentation is informed by what is called pragma-dialectics. In the version of pragma-dialectics developed by Frans van Eemeren \& Peter Houtlosser (2002) and extended by van Eemeren (2010), argumentation is defined as the pragmatic marriage of dialectic (the rational search for the best solution to a problem through dialogue) and rhetoric (the search for the best available discursive means to one's desired ends). Van Eemeren (2010) developed the concept of strategic maneuvering in pragma-dialectics to describe the ways that writers combine dialectical and rhetorical strategies in order to compose texts that are both reasonable (dialectic) and effective (rhetoric).

I am drawn to pragma-dialectics because it shifts the definition of argumentation away from claims supported by data, and toward discourse aimed to resolve a difference of opinion. This changes (it reframes) the tasks of a writer. This reframing was an epiphany for me. I had been frustrated with the lack of attention to the intellectual work of developing good claims through the process of drafting argumentative prose. Like others, I had been particularly irked by the power of the ACT writing test to shape classroom instruction. The ACT writing test asks students to identify their topic and invent a main claim very quickly, too quickly, in fact, almost arbitrarily.

Teachers feel intense pressure to teach to this test. Furthermore, the ubiquity of a Toulmin model-based understanding of argumentation has sanctioned the habit of beginning with a claim (I know what I believe; don't try to change my mind.) and moving 
quickly to brainstorming and organizing support for that claim. Then students keep moving forward, considering and including any necessary warrants to explain the move from data to claim, qualifying the force of the claim, and acknowledging possible rebutting conditions.

By contrast, the pragma-dialectical model for critical discussion, if used as an argument-writing heuristic, encourages writers to move through four phases, not necessarily linearly:

- the confrontation stage: identifying a difference of opinion

- the opening stage: establishing the terms and common starting points, i.e. the common ground between those who have the difference of opinion, perhaps the writer and the reader

- the argumentation stage: developing evidence and reasons to support standpoints and respond to critical questions

- and the concluding stage: evaluating the results of this argumentation on the merits, sometimes moving into a new confrontation stage when a new difference of opinion within the issue is identified.

This model of critical discussion was developed through a descriptive study of actual language use understood through the lens of the long philosophical tradition of dialectic. The purpose of dialectic is to come to the best possible solution to a problem through discussion.

By contrast, Stephen Toulmin's purpose in creating an argument model was to offer a critique of mathematical logic as a tool for assessing the strength of practical arguments. To this end, he looked to the practice of law. "In the studies which follow," he says by way of introduction to The Uses of Argument, "the nature of the rational process will be discussed with the 'jurisprudential analogy' in mind" (7). Why does this matter? Well, in law, it is not the lawyer's job to choose whether to support the plaintiff or the defendant. In law, the client chooses the lawyer to represent him, and the lawyer's job is to find the best available means of defending that client, of strengthening the case. A student writer, however, unless taking part in some school domain language game in which the roles are assigned, must develop his or her own standpoint as part of the composing process. Learning how to come up with a topic and deliberate among viewpoints when writing academic arguments is central to the endeavour. To this end, Stephen Toulmin's work is less helpful than others'.

In 1958, Stephen Toulmin wrote The Uses of Argument within the field of philosophy as a critique of the geometric approach to logical validity. In order to show that syllogistic reasoning is not the only way to argue logically, Toulmin developed a visual representation of argument structure. In his introduction, he explained the small scale of the unit for which he was designing a model: "An argument is like an organism. It has both a gross, anatomical structure and a finer, as-it-were physiological one.... The time has come to change the focus of our inquiry and to concentrate on this finer level." (87) While the book was not influential among philosophers in Britain, its innovative message was recognized by speech communication scholars in the United States. Application to written composition followed in subsequent decades. Even though Stephen Toulmin carefully defined the scope of his work as a description of the smallest units in arguments that justify pre-chosen claims, his model is currently used to teach the 
whole, macrocosmic structure and invention process of written argumentative texts. This constitutes a four-step retooling of his work: from philosophy to communication, from oral discourse to written prose, from microcosmic to macrocosmic structure, and from description to invention. I think that this has led to confusion.

\section{MICROCOSMIC MODEL/MACROCOSMIC APPLICATION}

The Toulmin model for understanding the structure of single argumentation--one claim, supported by one piece of data, whose relevance is explained by one warrant, with one modal qualifier signalling its degree of force or probability, with one nod to its exceptions or possible rebutting conditions--this microcosmic structure is used as a curriculum for teaching the macrocosmic composition of whole essays. This is problematic because the common expectation for longer argumentative papers is that they include multiple argumentation supported by subordinate or coordinative argument structures. While it is true that each claim within more complex argument structures can individually be examined for explicit or implied warrant, backing, qualifier and conditions of rebuttal, simply knowing these six elements does not help students to compose well-organized macrostructures.

\section{REBUTTING CONDITIONS ARE NOT REBUTTALS}

The definition of several terms are also confusing as a result of this application of Toulmin's critique of analytic philosophy to the macrocosmic invention stage of written composition. Confusion exists about the difference between qualifier and rebutting conditions, as Toulmin defined them, and the bigger units of an argument: qualifications and rebuttals of rebuttals, and the difference among the terms qualifier, qualification, rebuttal, condition, exception, and counterargument. We struggle to teach argumentation well in schools when teachers don't have uniform understandings--or even confidently unique--understandings of these terms.

Toulmin explains his terms by explicating the following argument: 


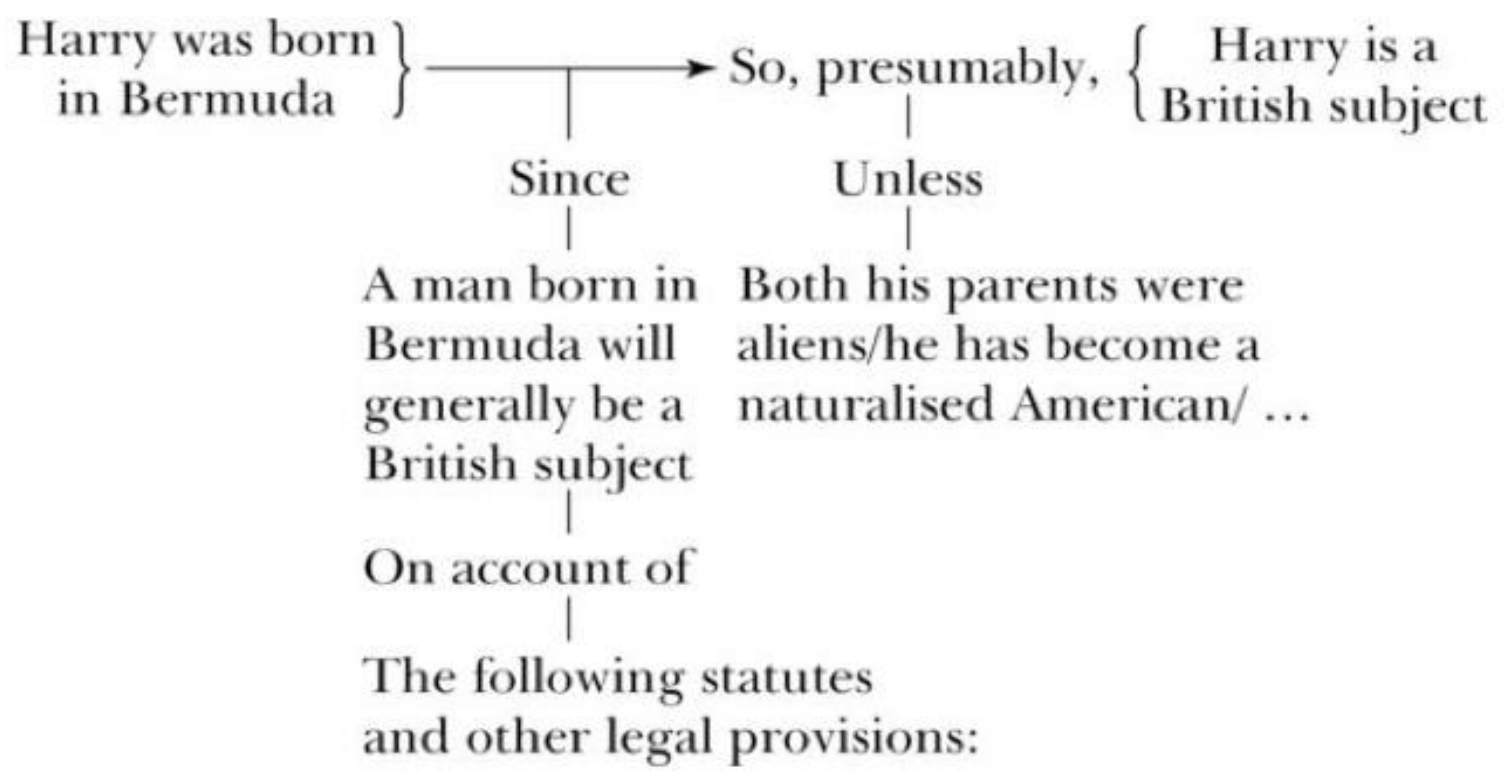

Following the pattern of the model:

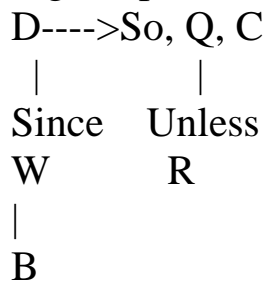

He defines his terms thus:

Just as a warrant (W) is itself neither a datum (D) nor a claim (C), since it implies in itself something about both $\mathrm{D}$ and C--namely, that the step from the one to the other is legitimate; so, in turn, $\mathrm{Q}$ and $\mathrm{R}$ are themselves distinct from $\mathrm{W}$, since they comment implicitly on the bearing of $\mathrm{W}$ on this step--qualifiers $(\mathrm{Q})$ indicating the strength conferred by the warrant on this step, conditions of rebuttal (R) indicating circumstances in which the general authority of the warrant would have to be set aside. To mark these further distinctions, we may write the qualifier (Q) immediately beside the conclusion which it qualifies (C), and the exceptional conditions which might be capable of defeating or rebutting the warranted conclusion (R) immediately below the qualifier. (93)

This diagram and its explanation are adapted in multiple and varying ways in writing textbooks.

There is confusion over the difference between a modal qualifier and a qualification. The former is a single word such as "presumably" in Toulmin's example, or probably, maybe, or to indicate strength, definitely. Outside of school, when we ask for qualifications or ask someone to qualify a statement, we are often asking for fully articulated conditions of exception. This is closer to what Toulmin called the rebuttal. 
In Toulmin's example, the rebuttal is a mention of the hypothetical conditions under which the claim might not be true: if Harry had, despite having been born in Bermuda, sometime later become a naturalized American, then he would not be a British citizen. Confusingly, the word "rebuttal" in common legal discursive practice and secondary school debate is used to mean a fully articulated counter-argument, or countercounter argument.

In the teaching of writing in secondary schools, students are often asked to include a counter-argument and a rebuttal of that counter-argument in their papers. When the Toulmin model diagram is referenced as an aid to organization, and if teachers are trying to teach students to add fully articulated counter-arguments, then they may use the word rebuttal or leave it out and replace it with the word response to describe the act of undermining the strength of this counterargument in order to maintain the persuasiveness of their initial standpoint.

Illustrating the potential confusion caused by conflicting definitions of these little words, in Hillocks' (2011) book on argumentative writing, the word "Rebuttal" appears in his Toulmin model diagram. However, Hillocks subsequently dispenses with this word in the body of his text, mentioning it nowhere. Instead of including the concept of "conditions of rebuttal" that Toulmin includes in his structure, Hillocks teaches teachers that because argumentation concerns matters of probability, "two other elements are necessary: qualifications and counterarguments." He encourages the use of qualifying terms: "probably, very likely, almost certainly, and so forth," staying close to Toulmin's text. But the use to which he puts counterarguments differs from Toulmin's rebutting conditions. Hillocks states, "The very idea that we are dealing with arguments of probability suggests that differing claims are likely to exist," and therefore, if hoping to make a persuasive argument, writers "would have to make a counterargument." Readers are left here without a clear explanation. Is the counterargument the summary of the standpoint and reasons of the imagined audience with whom the writer has a difference of opinion; or is it an argument whose standpoint is that the reasons or warrants of his antagonists are weak? Hillocks doesn't say, and this is not clarified for students. What is clear is a need for more thoroughgoing dialectic, as evidenced by the adaptation to the Toulmin model not only in the work of Hillocks (2011) but also Williams and Colomb (2001) and Smith, Wilhelm, and Frederickson (2012). All of these authors supplement the "rebutting conditions" in Toulmin's actual work with "counterargument" or "acknowledgment" and "response."

\section{THE DIFFICULTY WITH WARRANTS}

There is also significant confusion about how to help students learn to identify and to invent warrants, if the number of articles published in English Journal on the topic is any indication (Anderson and Hamel 1991; Warren 2010; Hillocks 2010). In Toulmin's model, the warrant links one's data to one's claim: "These may normally be written very briefly (in the form of 'If $\mathrm{D}$, then $\mathrm{C}^{\prime}$ ); [or they can be expanded] 'Data such as D entitle one to draw conclusion, or make claims, such as $\mathrm{C}^{\prime}$, or alternatively 'Given data $\mathrm{D}$, one may take it that C."' (Toulmin 91). Yet it is rare to find examples of warrants in this "ifthen" form. In their article, "Teaching Argument as a Criteria-Driven Process," Anderson 
and Hamel exemplify this difficulty. Their own definitions of warrants and backing seem at odds with the example they give. Here are their definitions:

Warrant: So what? (What's the principle or rule being cited to connect the grounds to the claim?)

Backing: What's the ultimate principle, theory, or tradition underlying the warrant? (or, What makes you think so?)

And here are their examples; notice that the "if-then" statement is listed as backing rather than warrant:

So what? That isn't fair. I deserve a chance.

What makes you think so? Fairness is an important principle for students to learn in sports. If students appear to be able to participate effectively, they should be given a chance to show their competence in a game. (44)

In my experience, possessing a declarative knowledge of the definitions of warrants and backing does not easily translate into a procedural ability to identify them in everyday usage. Nor does it help writers to decide when warrants and backing need to be stated explicitly and when they can be left to readers' implicit understanding.

\section{DEFENSIVENESS TRAINING}

Fourth (and I think most importantly), I think we in the United States have a systemic problem that an overreliance on the Toulmin model is not helping us to fix. Teachers feel pressured to coach students to quickly defend and justify their opinions in order to succeed on timed writing tests like the ACT. More time seems to be devoted to teaching the process of justifying opinions (Toulmin's focus) than learning to develop nuanced positions through a process of critical deliberation. This troubles me because cognitive scientists tell us that humans have a natural tendency toward confirmation bias--toward noticing the data that supports beliefs. This is an adaptive strategy for our minds. Because our five senses can collect more information than we can process, we can only attend to the information that seems important. Unfortunately, this selection process tends to blind us to disconfirming evidence. Unless we are taught to slow down, to actively seek data that might support multiple viewpoints, humans tend not to. It is my hope that we develop more curricula that treats written argumentation as a means of critically assessing the strength of opposing viewpoints, that is, argumentative writing as a tool for coming to conclusions about which answer is the strongest one with regard to the questions that we ask.

\section{CONFERRING EFFECTIVELY}

How can pragma-dialectics help teachers to supplement the lack of attention to deliberation in the Toulmin model? It can provide even more questions to ask of writers, critical questions to add to the ones offered by Toulmin to help foster the reasonableness and the strength of argumentation. Rather than simplistically equating argumentative writing and persuasive writing, pragma-dialectics offers a more nuanced definition. Argumentative texts are understood as turns of talk in a critical discussion (van Eemeren 
and Grootendorst 1984, 1992, 2004). Pragma-dialectics understands the writer to be a participant in a critical discussion during which he or she tries to support a standpoint (claim) in the face of the reader's doubts or criticisms. While the aim of resolving a difference of opinion with one's audience and the aim of persuading one's audience are similar (because one way to resolve a difference of opinion is to effectively persuade one's audience to agree with your standpoint), they are not identical. Pragma-dialectics (as its name suggests) enriches argumentation by reference to the long tradition of dialectic, reminding students from the outset that their purpose is to evoke a dialogue, to try to live up to the ideal of a critical discussion--even if the text has a single author whose audience is addressed in the imagination as he or she composes.

In Toulmin's The Uses of Argument, he suggests that data is given to support a claim when an audience asks, "What have you got to go on?" (Smith, Wilhelm \& Fredricksen translate this as "What makes you say so?") Arguers are prompted to articulate their warrant when asked, "How is that relevant?" ("So what?" ask Smith, Wilhelm \& Fredricksen.) In addition to these questions, there are others that teachers can use to confer effectively.

At the most fundamental level, "How's it going?" is the most helpful step to begin a conversation with students about their work (Anderson 2000). Listening carefully to a student's answer, writing coaches can determine whether the student has a topic or not. By thinking through the stages of a critical discussion, writing coaches can help students to understand their role as interlocutors tasked with identifying and then working to resolve a difference of opinion. I suggest the following questions for use in writing conferences.

\section{If a student seems to be working on the confrontation stage:}

- What's the issue that you are writing about?

- Who is your audience for this paper? Is there an audience other than your teacher?

- Is there a difference of opinion about this issue?

- What are the different points of view with regard to this issue?

- Which point(s) of view seem(s) best to you?

- Who might doubt that opinion or disagree with that point of view?

\section{If the student seems to be working on the opening stage:}

- When it comes to this issue, what do the possible points of view have in common?

- What do you and your readers probably agree about when it comes to this issue?

- What are the constraints of your assignment? Does the assignment give clear instructions about length, genre, and definition of effective writing? ${ }^{1}$

1 Graded written work within the education domain almost always has both a primary and a secondary rhetorical context, even if the teacher is the only audience. The teacher or some other audience may be the interlocutor in a critical dialogue about the issue, but always in the background is the primary context of schooling - the issue of a student's satisfactory progress toward learning goals. In effect, every graded assignment asks a student: Are you capable of effectively accomplishing this composing task? Every assignment handed in asserts the claim: Yes, I am capable of effectively accomplishing this composing task. The extent to which the composition is effective argumentation 


\section{If the student seems to be working on the argumentation stage:}

- How is your text going to resolve a difference of opinion?

- What reasons can you imagine to support that point of view?

- Are you making a cause and effect argument, a symptomatic argument, or an argument by analogy?

- It sounds like you are making a cause \& effect argument;

$\circ$ will that effect indeed follow? Or could it be achieved more easily by way of another measure?

0 is the effect of the cause really as good or as bad as you assert?

- are there any other good or bad side-effects that will follow?

- It sounds like you are making a symptomatic argument;

$\circ$ is that quality also a symptom of anything else?

- do things like that have other typical characteristics as well?

- It sounds like you are making an argument by analogy;

0 have you accurately described both of the situations or things you are comparing?

○ have you clarified the resemblance between them?

- are there crucial differences between them? Are there perhaps other situations or things that better resemble the present case? (Adapted from van Eemeren \& Grootendorst 1992: 101, 102)

\section{If the student seems to be working on the conclusion stage:}

- Which stance on this issue seems the strongest?

- Are the arguments for that standpoint completely persuasive to you?

- Do you have any doubts about them?

- Have you changed your mind about this issue through the process of writing this paper?

- Did you discover any differences of opinion about sub-issues while you worked on this paper?

- What do you think that readers should consider next in order to understand either the causes or the consequences of this difference of opinion?

\section{CONCLUSION}

If teachers of writing were to strategically ask these questions while conferring with students, the latter would improve not only their persuasiveness (rhetoric), but also their reasonableness (dialectic). Teachers and tutors can help students not only to support points of view, but also to determine those points of view though critical thinking. Eventually, the questions that teachers ask may become the questions that students ask themselves. Conferring with pragma-dialectic critical questions in mind can help students to learn which questions to ask themselves during the invention stage of the

to the secondary rhetorical situation is implicit argumentation in support of the claim to the student's intellectual capabilities. 
writing process to evaluate which claim should be their main claim, which solution, among all of the possible solutions, should be the one that they advocate.

ACKNOWLEDGEMENTS: I am indebted to all of the members of the Argumentation and Rhetoric research program at the University of Amsterdam. Thank you for welcoming me so warmly for a year-long research sabbatical, during which I studied pragma-dialectics. Special thanks go to Bart Garssen and José Plug for agreeing to let me be a visiting scholar, to Annemiek Hoffer for managing the details, to all who presented during Friday research colloquia, to Frans van Eemeren for long lunch conversations, and to Ingeborg van der Geest for sharing her desk and her friendship.

\section{REFERENCES}

Anderson, E. M., \& Hamel, F. L. (1991). Teaching argument as a criteria-driven process. English Journal, 80(7), 43-49.

Anderson, C. (2000). How's It Going? A practical guide to conferring with student writers. Portsmouth, NH: Heinemann.

Chin, C. \& Osborne, J. (2010). Supporting argumentation through students' questions: Case studies in science classrooms. Journal of the Learning Sciences, 19(2), 230284.

Eemeren, F. H. van (2010). Strategic maneuvering in argumentative discourse: Extending the pragma-dialectical theory of argumentation. Amsterdam; Philadelphia: John Benjamins.

Eemeren, F. H. van \& R. Grootendorst (1984). Speech acts in argumentative discussions: A theoretical model for the analysis of discussions directed towards solving conflicts of opinion. Dordrecht, Holland; Cinnaminson, U.S.A: Foris Publications.

Eemeren, F.H. van \& R. Grootendorst (1992). Argumentation, communication and fallacies: A pragma-dialectical perspective. Hillsdale, New Jersey: Lawrence Erlbaum Associates, Inc.

Eemeren, F. H. van \& R. Grootendorst (2004). A systematic theory of argumentation: The pragma-dialectical approach. New York: Cambridge University Press.

Eemeren, F.H. van \& P. Houtlosser (2002). Strategic manoeuvring. Maintaining a delicate balance. In: F.H. van Eemeren \& P. Houtlosser (Eds.), Dialectic and Rhetoric: The Warp and Woof of Argumentation Analysis (pp. 131-160). Dordrecht: Kluwer Academic Publishers.

Enduran, S., Osborne, J. F., \& Simon, S. (2004). Enhancing the quality of argument in school science. Journal of Research in Science Teaching, 41(10), 994-1020.

Hillocks, G. Jr. (2010). Teaching argument for critical thinking and writing: An introduction. English Journal, 99(6), 24-32.

Hillocks, G. Jr. (2011). Teaching argument writing grades 6-12: Supporting claims with relevant evidence and clear reasoning. Portsmouth, NH: Heinemann.

Krummheuer, G. (1995). The ethnography of argumentation. In P. Cobb \& H. Bauersfeld (Eds.) The Emergence of mathematical meaning: Interaction in classroom cultures (pp. 229-269) Hillsdale, NJ: Erlbaum. 
Ramage, J., J. Bean, \& J. Johnson (2012). Writing arguments: A rhetoric with readings. New Jersey: Longman

Smith, M., J. Wilhelm, \& J. Fredricksen (2012). Oh yeah? Putting argument to work both in school and out. Portsmouth, NH: Heinemann.

Toulmin, S. E. (1958). The uses of argument. Cambridge: Cambridge University Press.

Warren, J. E. (2010). Taming the warrant in Toulmin's model of argument. English Journal, 99(6), 41-46.

Williams, J. \& G. Colomb. (2001). The craft of argument. New Jersey: Longman. 